\title{
Hour Times Femtogram per Milliliter per Kilogram per Meter Squared
}

National Cancer Institute

\section{Source}

National Cancer Institute. Hour Times Femtogram per Milliliter per Kilogram per Meter

Squared. NCI Thesaurus. Code C111210.

Hours times femtograms per milliliter, divided by kilograms per meter squared. 